\title{
As Relações entre Teoria Crítica e Psicanálise
}

Frederico Souza de Queiroz Assis

\section{Resumo:}

$\mathrm{O}$ artigo tem o objetivo de identificar como se inter-relacionam duas correntes teóricas de grande influência acadêmica, designadamente as formuladas por Karl Marx e Sigmund Freud, apresentando seus eixos temáticos e autores principais. Cabe observar como a teoria crítica - em particular a desenvolvida pela Escola de Frankfurt - apropria-se de um aparato de categorias psicanalíticas para explicar fenômenos socioeconômicos relevantes para a doutrina marxista, atentando para as suas variações conceituais, não raro, como decorrência de transformações histórico-estruturais.

Palavras-chave: teoria crítica - psicanálise - freudo-marxismo - Escola de Frankfurt. 


\section{Introdução}

$\mathrm{O}$ artigo tem o objetivo de identificar como se inter-relacionam os desdobramentos de duas matrizes teóricas de grande influência acadêmica, designadamente as formuladas por Karl Marx e Sigmund Freud, apresentando seus eixos temáticos e autores principais. Cabe observar como a teoria crítica - em particular a desenvolvida pela Escola de Frankfurt - apropria-se de um aparato de categorias psicanalíticas para explicar fenômenos socioeconômicos relevantes para a doutrina marxista, atentando para as suas variações conceituais, não raro, como decorrência de transformações histórico-estruturais.

Associando primordialmente o vocabulário freudiano (como libido sexual, aparelho pulsional e conflitos infantis) a temáticas marxistas (como estrutura econômica, sistema de produção capitalista e exploração de classes), tais teóricos levantam questões inovadoras - na medida em que incorporam fatores subjetivos na teorização sobre o desenvolvimento histórico humano que, inequivocamente, contribuem para o acréscimo qualitativo do marxismo ocidental em geral.

Diante disso, o artigo divide-se em quatro partes, a saber: I) um histórico panorâmico das relações entre freudismo e teoria crítica, seus desdobramentos e impactos; 2) a concepção freudo-marxista das décadas de vinte e trinta, com foco na produção teórica de Erich Fromm; 3) a chegada do freudismo entre os frankfurteanos, em especial, a incorporação da psicanálise realizada por Max Horkheimer e Theodor W. Adorno, ressaltando suas convergências e inflexões em relação ao movimento precedente; 4) a recepção da psicanálise em Herbert Marcuse, dando relevo ao aspecto "utópico" conferido à sua teoria, a qual resgata um projeto emancipatório, apresentando os conceitos desenvolvidos dentro dessa perspectiva. Por fim, ainda, faremos breves considerações à guisa de uma conclusão relativa ao movimento que propôs a aliança intelectual de Freud e Marx.

\section{A Aproximação Entre as Duas Correntes Teóricas}

A tentativa de integrar o freudismo e o marxismo no nível da teoria, como sugere Rouanet (200I), teve sua gênese propiciada por dois acontecimentos históricos que modificariam o enfoque metodológico para a "valorização do fator subjetivo da história" (p. I3). A Revolução Russa de I9I7 e a ascensão de Hitler ao poder na Alemanha em 1933 exigem explicações de como a ideologia operou nas massas, em ambos os casos, de modo descompassado com a realidade objetiva, e de tal maneira que sua penetração configura-se como elemento necessário para a coesão social que permitia a dominação política. 
Nesse sentido, a psicanálise, enquanto doutrina do funcionamento psíquico da ação irracional, parecia oferecer os instrumentos para a compreensão do enigma (p. I4).

Assim, o principal tema nessa fase inicial de encontro entre as duas correntes teóricas é a questão de como a ideologia legitima a exploração, por meio da modelagem do aparelho psíquico individual, o que parecia poder ser resolvido pela interação com categorias explicativas da psicanálise. Em outras palavras, a pergunta capital formulada no início do debate freudo-marxista das décadas de vinte e trinta era como é possível que a maioria oprimida aceite sua opressão pela minoria; e investigar, deste modo, os mecanismos de interiorização que tornavam isso exequível.

De início, houve um relativo interesse soviético nos textos de Freud, em especial, à época da construção do "homem novo" nos primeiros anos da revolução. Porém, com a inflexão stalinista, a psicanálise passou a ser considerada um fruto da "teoria burguesa", sendo, como era de se esperar, banida dos círculos acadêmicos daquele país, dando lugar à reflexologia de Pavlov (com orientações behavioristas), a única escola da Psicologia que poderia ser enquadrada "no universo estático das Ciências Naturais" (ibid., p. I6) - lugar em que, também, o marxismo foi colocado.

Em outros locais, entretanto, floresceram as primeiras tentativas de fundir os dois sistemas teóricos. Psicanalistas como Siegfried Bernfeld, Otto Fenichel e Paul Federn elaboraram as obras dos primeiros tempos, embora sem grande êxito (Jay, I974, p. I5I). Ainda que negassem pressupostos da reflexologia, esses autores tentam ao máximo reificar e naturalizar a psicanálise, tomando-a como Ciência Natural - característica, na verdade, presente também nos demais autores, como Wilhelm Reich e Erich Fromm, sendo exatamente esses dois autores os que gozavam de maior projeção e relevância acadêmica naquele período.

Em seguida, um passo importante para a evolução do debate foi dado com a tentativa do Instituto de Pesquisa Social de introduzir a psicanálise em sua teoria crítica (Jay, p. I52). Filósofos vinculados ao instituto frankfurteano demonstravam grande interesse pela temática desde o inicio da década de vinte, quando Max Horkheimer já pensava nas relações entre marxismo e psicanálise, tendo, inclusive, influenciado Theodor Adorno a escrever, em I927, um "trabalho que vinculava a psicanálise com a fenomenologia transcendental de Cornelius" (ibid., p. I53). Horkheimer, assim, tentou persuadir Karl Landauer (que havia sido aluno de Freud) para fundar o Instituto Psicanalítico de Frankfurt, fato que se concretizou em I6 de fevereiro de I929, e que se converteu na primeira organização declaradamente freudiana a se vincular, mesmo que indiretamente, a uma universidade alemã (ibid., p.I54), mantendo relações estreitas com o Instituto de Pesquisa Social. Além de Landauer, eram 
membros permanentes do Instituto Psicanalítico Heinrich Meng, Erich Fromm (que também era ligado formalmente ao outro instituto) e sua esposa Frieda Fromm-Reichmann - sem contar outras figuras de destaque na área que lá ministravam conferências.

Também, no Instituto de Pesquisa Social, desenvolveram-se trabalhos significativos que buscaram "uma teorização freudo-marxista flexível, cuja dinâmica se basearia em uma metodologia dialética, de inspiração hegeliana e marxista" (Freitag, I986, pp. I4-5). Diante dessa proposta, Horkheimer e Fromm coordenam, em I936, os Studien zu Autoritaet und Familie (Estudos sobre a Autoridade e Família), que retomam a discussão iniciada na década de vinte. De modo geral, a Escola de Frankfurt sustenta "a profunda preocupação em integrar o nível macroteórico (produção capitalista) com o nível micro (indivíduo sexualmente reprimido), mediatizados pela estrutura familiar autoritária" (ibid., p. I4).

Tendo isso em vista, o desenvolvimento histórico da teoria crítica foi permeado por categorias freudianas, de modo que estas enriqueceram seu enfoque marxista, tornando-o cada vez mais heterodoxo.

\section{Os Freudo-Marxistas das Décadas de Vinte e Trinta: Erich Fromm}

Nessa seção do trabalho, serão avaliadas as contribuições do freudomarxismo dos anos vinte e trinta para o desenvolvimento temático (simultâneo e posterior) realizado pelos frankfurteanos. ${ }^{\text {I }}$ Tendo como foco, fundamentalmente, a "teoria da ideologia", os freudo-marxistas estabelecem a primeira tentativa bem-sucedida de associar o pensamento de Freud ao de Marx. Seus principais expoentes foram Wilhelm Reich e Erich Fromm, sendo o último, aqui, observado com maior atenção.

Cabe, entretanto, ainda que de modo sucinto, mencionar a importância teórica de Reich - e aí costuma-se dividir sua carreira intelectual entre o "bom Reich" (até I934) e o "mau Reich" - no debate em torno de Marx e Freud, por sua preocupação em tentar compreender o hiato presente entre a existência na sociedade e a consciência social, relacionando as formas de condicionamento ideológico à teoria da genitalidade e à teoria do caráter. Embora pioneiro do

I Como propõe Rouanet, embora Fromm tenha se vinculado ao Instituto de Pesquisa Social, cabe distinguir o termo "frankturteanos" (aplicado, nesse trabalho, fazendo referência a Adorno, Horkheimer e Marcuse) do termo "freudo-marxistas das décadas de vinte e trinta" (em alusão a Reich e Fromm). 
freudo-marxismo dos anos vinte e trinta, o prestígio acadêmico das teorias reichianas declinou vertiginosamente conforme o interesse central do autor foi deslocado e sua aproximação teórica com o freudismo e marxismo foi atenuada - a tal ponto de o Reich do "orgônio" ${ }^{2}$ ser, por muitos, ridicularizado, o que culminaria na sua expulsão do Partido Comunista e do movimento psicanalítico.

Do mesmo modo, o Fromm apresentado aqui será o anterior ao "revisionismo psicanalítico" - o qual receberia severas críticas de Marcuse, que serão expostas em outra seção do trabalho - e que pode ser circunscrito propriamente dentro do freudo-marxismo. Nascido em Frankfurt, em I900, membro do Instituto de Pesquisa Social e do Instituto Psicanalítico, Erich Fromm foi muito influenciado pelo ambiente social em que viveu para, enfim, "encontrar-se com Marx e Freud" (Fromm, I963) e formular suas teorias relativas à ideologia e sua conexão com a estrutura libidinal do homem. Com participação fundamental em tal debate teórico, a investigação central de Fromm é justamente essa interação libido-sociedade, o que "consistia em compreender uma conduta motivada inconscientemente nos termos do efeito da superestrutura socioeconômica sobre os impulsos psíquicos básicos" (Jay, p. I6I). Assim, utilizando-se de instrumentos psicanalíticos, Fromm tenta demonstrar como a base econômica - central na teoria marxista - traduz-se na superestrutura ideológica. Deste modo, interpretar como toda a estrutura psíquica é modelada pelas condições socioeconômicas exige que se observe o conceito de caráter social.

Se Freud traz uma inovação conceitual ao apresentar sua concepção dinâmica de caráter - que superava as visões da escola behaviorista, a qual considerava caráter como sinônimo de traços de comportamento (Fromm, p. 7I) - que depende das "vicissitudes da história individual" (Rouanet, p. 54, grifo nosso); Fromm, por sua vez, inova ao apresentar a ideia de determinação social do caráter, cuja formação é historicamente determinada. Como aponta Rouanet, "cada época suscita o tipo de caráter que necessita" (p. 54).

Se a estrutura histórica determina o conteúdo do caráter, a sua fecundação formal encontra-se nos conflitos infantis, em particular, no conflito edipiano e na relação final com o Pai. Com a finalização do processo edipiano, o indivíduo identifica-se com o Pai e introjeta seus valores - em uma instância psíquica recém-criada, o Superego - os quais são, em última instância, os valores sociais vigentes, ou seja, os valores da ideologia mediatizados pela autoridade paterna,

2 Conceito reichiano que descreve a "substância primordial subjacente tanto à vida psíquica do homem quanto à estrutura da Via-Láctea, e que explica a formação das galáxias, como a origem do câncer” (Rouanet, p. 26). 
reproduzidos de forma constante por aparelhos ideológicos, como a escola e a mídia de massas.

Em resumo, "a base gera o caráter social, que condiciona as ideias e valores, que constituem a ideologia; mas essas ideias e valores, numa ação de retorno, refluem para o caráter social, reforçando-o, o que por sua vez consolida a base econômica" (Rouanet, p. 55). Diante desse quadro, a estrutura libidinal tem, por um lado, a função de preservar as estruturas sociais vigentes, ao mesmo tempo em que é produzida pelas mesmas circunstâncias materiais.

O período intelectual do freudo-marxismo anterior ao revisionismo de Fromm contribui de modo expressivo para a reflexão em torno de Marx e Freud na medida em que antecipa temas discutidos pela Escola de Frankfurt, ainda que, para os últimos, sejam avaliados sob uma perspectiva pessimista, nomeadamente para Adorno e Horkheimer, que serão abordados a seguir.

\section{O Encontro da Escola de Frankfurt com Freud: Horkheimer e Adorno}

Os filósofos alemães Max Horkheimer e Theodor Adorno, no que concerne à recepção do freudismo, apresentam uma série de convergências conceituais com os freudo-marxistas das décadas de vinte e trinta, absorvendo distintas contribuições teóricas - a criação do Instituto Psicanalítico serve, no fundo, para facilitar a circulação de ideias entre as duas correntes (Rouanet, p. 69) - mas rompem com Fromm logo que diferenças radicais de opinião ficam explícitas pelo "revisionismo culturalista" constitutivo do neofreudismo frommiano.

Algumas obras iniciais acerca da intersecção entre Marx e Freud começam a evidenciar a originalidade teórica dos dois autores frankfurteanos. Um texto inaugural, que proclama a necessidade de encontrar um "suplemento psicológico à teoria marxista" (Jay, p. I74), é História e Psicologia de Horkheimer, o qual visa fazer uma "caracterização do papel da Psicologia no âmbito de uma teoria da História ao nível das Ciências Sociais" (Horkheimer, I990). Nesse mesmo sentido, apesar de mais tardiamente (I950), a obra de Adorno A Personalidade Autoritária se caracteriza como uma reflexão profunda na qual o autor realiza um amplo trabalho empírico no contexto norte-americano (onde Adorno está exilado), de modo a construir uma tipologia caractereológica (Freitag, pp. I8-9).

No conjunto, é importante verificar a mudança no conceito de opressão como decorrência da mudança na situação histórica em que os diferentes autores estão inseridos. Se, antes, o contexto vivido era de grande depressão econômica, agora, apresenta-se na história a abundância material do pós-guerra. Então, 
a ideologia no presente torna-se, inversamente, a utopia realizada. "A síntese unidimensional em que a realidade se confunde com a utopia (...) repousa, assim, sobre a unidade repressiva de uma pseudo-racionalidade e de uma pseudo-realidade. (...) Mas se a falsa consciência do passado significava aceitar uma realidade repressiva que se apresentava com tal, a atual significa aceitar uma realidade que se apresenta como não-repressiva, apesar de constituída, em sua estrutura mais íntima, pela repressão” (Rouanet, p. 73). Assim, essa modificação conceitual caracteriza-se tanto por aumentar o número de pessoas sujeitas à dominação, quanto por contornar os fenômenos psicológicos de um modo diferenciado em seu conteúdo.

Outro ponto importante desenvolvido por Adorno e Horkheimer, a partir de uma leitura freudiana, é a sua crítica da cultura. "Partilham, com a psicanálise, a visão pessimista básica de que a civilização só é possível ao preço da mutilação do homem” (Rouanet, p. II7). A visão é exposta com o mesmo significado na célebre frase de Walter Benjamin (I993): "Nunca houve um monumento da cultura que não fosse também um monumento da barbárie". Assim, toda arte e toda a cultura são constituídas por "sofrimento sublimado", "cristalização estruturada da renúncia pulsional" (Rouanet, p. II7). Nesse sentido, a crítica da cultura de Adorno e Horkheimer mostra-se cada vez mais próxima da psicologia social de Freud, utilizando-se de conceitos psicanalíticos - como o de identificação e o de projeção - para a compreensão da indústria cultural.

Ainda, Horkheimer e Adorno promovem uma crítica ao próprio freudismo, pois, enquanto parte da cultura, é ideológico e passível de "falsificações"; do mesmo modo, outros elementos do freudismo servem de instrumento para criticar a sua própria teorização. Como coloca Rouanet, "se a Escola de Frankfurt é a crítica da ideologia e a crítica da cultura, o é, em grande parte, através de Marx e Freud, mas o é, também, contra Marx e Freud" (p. 76). Também, a crítica dos dois autores ao freudismo é dirigida ao "desvio psicanalítico" decorrente do revisionismo da escola culturalista. Como o revisionismo elimina a teoria das pulsões, sua psicanálise aparece dessexualizada; ao suprimir a libido encerra-se, portanto, a possibilidade de crítica ideológica.

Em resumo, Adorno e Horkheimer dão um grande salto qualitativo nas abordagens teóricas críticas que incorporam a psicanálise. Sua contribuição nesse terreno é fundamental para o surgimento das reflexões de Herbert Marcuse, que apresenta uma diferença substancial em relação a esses dois autores: pensa tais questões a partir de uma perspectiva utópica, a qual veremos a seguir. 


\section{A Tendência Oculta em Psicanálise: o Pensamento de Marcuse}

Conforme apresenta Robinson (I97I, p. II6), "na década de 50, apareceram três livros que puseram em questão a interpretação dominante de Freud" justamente porque bebiam dos elementos condenados pelos teóricos mais ortodoxos, a saber, as incursões meta-históricas de Freud (ibid., p. II6). Um desses livros - e, reconhecidamente, o de maior relevância - é Eros $e$ Civilização de Herbert Marcuse, o qual observava no pensamento de Freud um viés de interpretação crítico, que denominou "tendência oculta em psicanálise" (Marcuse, I968). ${ }^{3}$

Nesse sentido, a reflexão marcuseana caracteriza-se pelo abandono do pessimismo encontrado em Adorno e Horkheimer, na medida em que pensa uma práxis revolucionária a partir da "reflexão sobre um novo projeto histórico" que exige "a utilização do freudismo para fundar a possibilidade de uma ordem não-repressiva" (Rouanet, p. 200). De todo modo, é evidente a aproximação de Marcuse com Horkheimer e Adorno - explicitada, inclusive, no prefácio de Eros e Civilização - essencialmente no campo da crítica da cultura, dentro do qual o autor compartilha inúmeros postulados básicos.

Ao mesmo tempo, depois de rejeitar brevemente Carl Jung e a "ala direita" da psicanálise, Marcuse voltava-se contra os neofreudianos (Jay, p. I85) e se transformava no crítico mais implacável do revisionismo. "Marcuse mostrou que os revisionistas tinham chegado às suas conclusões aperfeiçoadoras abandonando os fatos crus e desagradáveis da metapsicologia de Freud: o papel preponderante da sexualidade na psicologia humana, a função do inconsciente, a primazia da infância, o instinto de morte e a teoria do crime primordial. Portanto, eram culpados de covardia intelectual e superficialismo teórico" (Robinson, p. I53). Ao retirarem da sexualidade o papel central aferido por Freud, os revisionistas minimizavam o potencial crítico do freudismo, atrelando-o aos valores repressivos da ordem capitalista, adotando, pois, uma solução política reformista.

Dito isso, Marcuse descreve as características da sociedade industrial, na qual a dominação tornou-se total, ao mesmo tempo em que suas estruturas tornaram-se invisíveis (Rouanet, p. 20I) que se manifesta na unidimensionalização da realidade, integrando a consciência da sociedade, e que opera por meio de manipulações das necessidades por interesses constituídos (Marcuse, I967).

3 Os outros dois livros são: Freud and the Crisis of Our Culture, de Lionel Trilling; e Life Against Death, de Norman O. Brown. 
"Se os conceitos freudianos são indispensáveis, em geral, para compreender os mecanismos subjetivos da dominação, são especialmente necessários para compreender a estrutura e a forma de enraizamento psíquico da modalidade mais extrema de dominação, que é a representada pela sociedade unidimensional” (Rouanet, p. 226).

Nessa etapa do capitalismo, a forma de dominação não é mais justificada por meio da ideologia, mas, ao contrário, é legitimada pela possibilidade de gratificação no sistema, em um contexto de abundância material, de modo que, pela satisfação direta e imediata, assume o aspecto de dessublimação repressiva. Mas como "essa dessublimação visa, não promover a libertação real, mas aprisionar mais eficazmente os indivíduos nas malhas da ordem existente, é lícito falar em uma dessublimação (...) a serviço da repressão” (Rouanet, p. 233).

Transplantada para todas as esferas, também a economia reveste-se de uma aparência de liberalização sexual. Contudo, na verdade, essa economia libidinal - refletida, por exemplo, nas propagandas comerciais - que transforma o sexo em mercadoria, atua em favor da ordem capitalista estabelecida, conservando, de modo firme, seu teor essencialmente repressivo.

Marcuse, inclusive, argumenta que a realidade de sublimação mostrase preferível à de dessublimação repressiva, uma vez que, na primeira, o indivíduo poderia desenvolver um senso de consciência das privações infligidas a ele; enquanto que, na última, ele tem a ilusão de que suas pulsões eróticas são satisfeitas plenamente. Pelo conformismo, o impulso revolucionário é bloqueado. Em outros termos, "o capitalismo contemporâneo realizou exatamente o inverso de uma verdadeira emancipação da libido - isto é, a 'dessublimação repressiva', de uma sexualidade comercializada e pseudopermissiva, represando e anestesiando qualquer rebelião mais profunda dos impulsos eróticos" (Anderson, 2004, p. I03).

Além disso, Marcuse reinterpreta a hipótese freudiana do crime primordial por meio de uma "alegoria capitalista". Diante do mesmo processo edipiano, é traçado um paralelo no qual o empresário capitalista (Pai) é suplantado pelo proletariado (Irmãos), que, no final das contas, estabelecem os mesmo valores da ordem preexistente. "Essa analogia sugere o fracasso histórico da revolução proletária que (...) mesmo no momento de revolução, continuou a identificarse com o poder contra o qual se revoltava" (Robinson, p. I62) e que implica na reprodução sintética da tirania paterna/capitalista.

Por isso, a saída para a constituição de uma civilização não-repressiva exige a ressexualização do corpo todo - e não só dos genitais, como propunha Reich -, fazendo com que ele se torne "um órgão de prazer em vez de labuta e esforço. A ressexualização do corpo revitalizaria as energias libidinais da humanidade e garantiria o triunfo final de Eros sobre Tanatos" (ibid., p. I68). Nesse mesmo sentido, afirma Perry Anderson, "a emancipação do homem e da natureza 
coincidiriam então na libertação erótica" (p. I03), configurando, por fim, uma ordem de dessublimação não-repressiva.

Em suma, a recepção de Freud e Marx por Marcuse mostra-se original entre os frankfurteanos na medida em que sua "utopia órfica-narcisista supõe a possibilidade histórica de introduzir uma ordem nova, além da falsa consciência unidimensional, baseada em novas relações perceptivas e vitais com a natureza" (Rouanet, p. 254), e que lhe alça a um respeitável posto no que se refere às formulações teóricas críticas integradas ao freudismo.

\section{Considerações Finais}

O encontro entre freudismo e marxismo foi um notável aspecto que desempenhou um importante papel nos rumos do marxismo ocidental. A inovação temática, inaugurada pelos freudo-marxistas dos anos vinte e trinta, aprimorada pela Escola de Frankfurt, inicialmente, por Horkheimer e Adorno e, de modo subsequente, por Marcuse - e que, na realidade, dentro do círculo frankfurteano, não se encerra com esse último autor, em que se pese a reflexão de Jürgen Habermas acerca do tema, articulada à sua teoria da comunicação -, mostra-se presente como fonte em estudos cuja interpretação própria lhes conferiu novos desenhos, como em Althusser e em Sartre.

Se Freud e Marx detêm, por si só, um prestígio intelectual singular dentre todos os importantes teóricos da Idade Contemporânea, observar suas teorias de modo conjunto e articulado revela-se um exercício analítico, no mínimo, muito interessante.

\section{Referências Bibliográficas}

ANDERSON, Perry. Considerações sobre o marxismo ocidental. São Paulo: Boitempo, 2004.

BENJAMIN, Walter. "Sobre o conceito de história". In: Obras escolhidas: magia e técnica, arte e política. São Paulo: Brasiliense, I993.

FREITAG, Bárbara. A teoria crítica: ontem e hoje. São Paulo: Brasiliense, I986.

FROMM, Erich. Meu encontro com Marx e Freud. Rio de Janeiro: Jorge Zahar, I963.

HORKHEIMER, Max. "História e psicologia” In: Teoria crítica. São 
Paulo: Perspectiva; EDUSP, I990, t.I.

JAY, Martin. La imaginación dialética: una historia de la Escuela de Frankfurt. Madri: Taurus, I974.

MARCUSE, Herbert. Eros e civilização. Rio de Janeiro: Jorge Zahar, I968.

MARCUSE, Herbert. Ideologia da sociedade industrial. Rio de Janeiro: Jorge Zahar, 1967.

ROBINSON, Paul. Aesquerda freudiana. Rio de Janeiro: Givilização Brasileira, I97I.

ROUANET, Sérgio Paulo. Teoria crítica e psicanálise. Rio de Janeiro: Tempo Brasileiro, 200I.

Frederico Souza de Queiroz Assis é graduado em Relações Internacionais pela USP.

E-mail: fredericoassis@yahoo.com.br 